\title{
Discrimination in a Covert Methodology: An Analysis of Physical and Social Characteristics That Prohibit People from Becoming Employed
}

\author{
Steven V. Cates ${ }^{1}$, Heather Dana ${ }^{2}$ \\ ${ }^{1}$ Department of Business Administration, Kaplan University, Davenport, USA; ${ }^{2}$ Kaplan University, Davenport, USA. \\ Email: \{SCates, HDana\}@kaplan.edu
}

Received December $27^{\text {th }}, 2011$; revised February $9^{\text {th }}$, 2012; accepted February $19^{\text {th }}, 2012$

\begin{abstract}
Organizations all over the world are found guilty of using stereotypes to discriminate against applicants in the selection process for employment. This research seeks to answer the question what stereotypes are used to discriminate against people in the selection process and consequently provide an analysis of the physical and social characteristics that prohibit people from gaining employment. A sample of 87 working adults taking a Human Resources Management course were selected to complete a survey that questioned them on physical characteristics and how they affected their decisions on hiring or rejecting applicants. Historical research has held that interviews possess some stereotypes such as race, gender, age, height and weight to judge applicants rather than their skills, knowledge and ability to perform the job. Five hypotheses were posited for testing. Mixed support was provided that respondents ignore most stereotypical characteristics in the employment selection process but surprisingly strong support for one's appearance and dress was found. It is recommended that interviewers undertake detailed training, decrease stereotyping by focusing on job description and keep interviews job related. It is also wise for interviews to include tests when judging applicant's skills, knowledge and ability. Federal laws and the Equal Employment Opportunity Commission also serve to ensure that equal opportunity is granted to all and discrimination is avoided.
\end{abstract}

Keywords: Employment Selection; Discrimination; Stereotyping; Employment Law

\section{Introduction}

In today's modern society, people are still encountering challenges because of the prejudices of others. This prejudgment made of others leads to stereotyping. [1] describes stereotyping as the tendency to assign a person to a group or broad category and then attribute generalizations about that group to the person. Stereotype is a simplistic and often incorrect belief about the typical characteristics of a particular group of individuals [2]. Individuals on whom these stereotypes are placed experience great difficulty with social mobility pursuits, including that of obtaining lawful employment. The difficulty arises because the interviewers enter the interview with prejudices and stereotypes of individuals rather than an open mind to assess the individual's ability to perform the job. This leads to discrimination; the act of making distinctions in prejudicial treatment of or showing partiality against one or more individuals for the main purpose of declining the welfare of that individual or group of individuals. Discrimination suggests differences on the basis of protected characteristics that have no rational relationship to job performance [3].

The process of selection speaks to the act of determining the skills, abilities, and other attributes an individual needs to perform a specific job [1]. Interviews and tests are the main processes used to select suitable employees for an organization. Employers have retreated from tests because of the idea that interviews were not subjected to the same firm standards as tests. They thought that because interviews were subjective, it was not flexible to scientific scrutiny and they only had to refrain from discriminatory questions to avoid discrimination lawsuits. For this reason, many employers used unstructured and non-scored interviews to avoid having to validate them in the case of an adverse effect on minority or female applicants. In 1988, the legal liability of interviewing was increased when the U. S. Supreme Court ruled in Watson vs. Fort Worth Bank and Trust that employers should be able to prove that subjective selection procedures such as interviews are job-related if they have adverse effect on applicants [3]. It is evident that a subjective procedure like interview would have a low reliability and validity 
rate without some structure and system of scoring. A system of measurement is needed to accurately assess each individual's skills, abilities and attributes needed to perform the specific job and in selecting the most suitable candidate. The year 1988 spoke to this respect.

\section{Purpose of the Paper}

The literature indicates a number of studies that suggest why discrimination persists in the U.S. This paper will attempt to identify those reasons that create a discriminatory environment in the employment setting. This paper will explore why those illegal practices continue and provide suggestions to eradicate them from organizations.

\section{Literature Review}

It is essential for interviewers to avoid judgment errors and bias when evaluating applicants. However, the subjectivity of interviews again lends itself to several types of judgment errors; these include the halo error, leniency, severity, and central-tendency errors, contrast effect, similarity effect, first impression error and of course stereotyping. Halo errors are made when an applicant is rated equally on all performance dimensions instead of identifying areas of strength and weaknesses. Leniency, severity and central-tendency errors are made when the differences in an interview performance is ignored and all applicants are given high, low or average ratings respectively. This becomes a greater problem if different interviewers use different standards. Contrast effect occurs when an applicant is given a rating higher than deserved after being interviewed by a weak candidate, or a lower than deserved rating after a strong candidate is interviewed. Similarity effect is giving applicants a high rate because they are similar to the interviewer, while first impression error is made when an applicant is rejected for a job because of the interviewer's first impressions [3]. Stereotyping as previously discussed is still the most frequently used judgment error that discriminates and prohibit people from gaining employment. Unstructured interviews present the grounds for much of this stereotyping and discrimination because they are low in reliability and validity, while tests are high in these areas. Structured interviews are better because they have a high level of validity and reliability and a low level of adverse impact for the organization, while unstructured interviews have a moderate to high level of adverse impact [3].

[4] brings to light the perspective that diversity in the workforce does not always provide an enjoyable environment. Because of potential bogus claims of discrimination many employees feel that they must walk on egg shells to avoid the company the risks and costs involved in litigation. This feeling leads to an adverse reaction that the diversity intended to bring. Alternatively, it is a known fact that the failure to diversify your workforce will likely have unpleasant consequences [4]. [4] acknowledges the possible dysfunctional side that can be present in a diverse workplace.

Some common characteristics used to discriminate against individuals in the selection process are race, color, gender, age, disability, religion, pregnancy or marital status, nationality, political opinion, criminal record, social origin, ethnicity, medical record, impairment, sexual preference and trade union activity. Interviews breathe several disadvantages because subjective evaluations are made. Decisions and impressions are formed within the first 35 seconds of meeting someone. The remainder of the interview is then used to validate or justify the original impression. The interviewers also form stereotypes about the characteristics needed for the success of the job. Research shows disproportionate rates of selection between minority and non-minority members using interviews. Interviews don't give much evidence of validity of the selection procedure and it is not as reliable as tests [5]. In Title VII of the Civil Rights Act of 1964 individuals are protected against employment discrimination on the grounds of color, race, national origin, sex, and religion. This Act refers to employers of 15 or more employees including state, local government, employment agencies, and the federal government. Title VII seeks to protect employees or applicants from discrimination because of his/her race or color in regard to hiring, termination, promotion, compensation, job training, or any other condition or privilege of employment. This Civil Rights Act also forbids employment decisions based on stereotypes about abilities, traits, or the performance of the individuals of a particular racial group and both intentional discrimination and neutral job policies that exclude minorities and that are not job related [6].

[6] further states that equal employment opportunity should not be denied on the basis of marriage to or association with a person of another race; membership in or association with ethnic based organizations or groups; or attendance or participation in schools or places of worship generally linked with certain minority groups. The Equal Employment Opportunity Commission (EEOC) has received several lawsuits and complaints of discrimination. The most obvious form of discrimination is disparate treatment in which individuals are treated differently because age, sex, skin color and nationality. This includes asking females about their ability to meet attendance requirements. Disparate treatment is also used when older applicants are denied because the employer believes they won't learn as quickly as younger applicants. Thirdly, this obvious discrimination is used when applicants with disabilities are required to have medical 
examinations or asked how their disability would affect their job performance. Asking only "foreign-looking” or "sounding" applicants to prove their eligibility to work in the U.S. is another form of disparate treatment [3]. The fiscal year of 2004 saw the EEOC receiving 27,696 charges of racial discrimination, 29,631 race charges were resolved and \$61.1 million in monetary benefits were recovered for the charging parties and other aggrieved individuals (excluding monetary benefits received through litigation). There has been an increase in the number of color discrimination charges received by the EEOC. Color bias findings have seen a $125 \%$ increase since the mid-1990's having 413 cases in the 1994 fiscal year to 932 in the 2004 fiscal year [6]. There needs to be more education on the part of employers to alleviate the race and color issue most often used to discriminate against applicants, as a matter of fact, there needs to be an international program educating people worldwide that we were all created equally and should be treated as such in all cases.

However, all is not lost, there are federal laws enforced to protect individuals from the unlawful exploitation of discrimination. The federal laws include the Age Discrimination Act 2004, Disability Discrimination Act 1992, Human Rights and Equal Opportunity Commission Act 1986, Racial Discrimination Act 1975 and Sexual Discrimination Act 1984 [7]. These laws ensure that individuals are not discriminated based on these physical characteristics. The primary Equal Employment Opportunity Laws cover the Equal Pay Act (1963), Civil Rights Act (Title VII) (1964 amended 1991), Age Discrimination in Employment Act (1967 amended 1987), Pregnancy Discrimination Act (1978), Immigration Reform and Control Act (1986) and the Americans with Disabilities Act (1990). The equal pay act prohibits discrimination in pay on the basis of gender, while the civil rights act prohibits discrimination in all areas of employment based on race, color, religion, national origin or gender. The age discrimination in employment act hinders discrimination on the basis of age for employees forty years and older and age-based mandatory retirement. The pregnancy discrimination act protects against discrimination based on pregnancy or pregnant related conditions. The covered employees should be treated in agreement with the organization's short-term-disability conditions. Individuals are protected against discrimination on the basis of national origin under the immigration reform and control act. This act requires employers to verify eligibility for employment of all applicants. Americans with disability act protects against discrimination on the basis of disabilities that have no effect on job performance. It requires "reasonable accommodation" of all qualified applicants with disabilities [3]. Laws are essential to ensure equal and fair employment opportunities for all applicants and employees alike, regardless of their differences.

By evaluating the tools used to hire in terms of their accuracy and fairness, employers would have met most of their legal obligations. The employer's primary legal obligation is to make hiring decisions without stereotypes on personal characteristics such as age, gender, race, disability or religion. By conducting a work analysis and developing a Performance Attributes Matrix, managers would have ensured that their hiring decisions are jobrelated and not discriminatory. The other legal obligation is to monitor the hiring process by first making certain that each applicant is treated similarly, excepting that of making reasonable accommodations for applicants with disabilities. Secondly, human resource managers have to determine if the hiring tools formulated for recruitment create any adverse impact against groups of individuals with protected characteristics. If adverse impacts are present in the hiring system and a lawsuit is brought against the organization, the managers will need to demonstrate the validity and how the issue causing the adverse impact is related to the job [3]. The validity of the hiring tool used is always of paramount importance in creating fair and equal prospect for all potential employees.

[3] hold that although there are many legal considerations to bear in mind, there are two legal points that must never be misunderstood. The first is that organizations have no legal requirements to validate their hiring system unless a plaintiff is victorious in demonstrating how it creates an adverse impact on them. Hiring tools should be constantly monitored and evaluated for validity to ensure the effectiveness of the process. This is not a legal compulsion unless the hiring tools are found to cause adverse impact on an individual or group of individuals. The point to note is that hiring tools that demonstrate adverse impact are not inevitably illegal. Two frequently used predictors that breathe adverse impact are measures of physical strength for which females frequently significantly score lower than men, and tests for general mental ability. Tests often adversely affect individuals of the Hispanic and Black groups. Though it is recommended for organization $\mathrm{s}$ to find equal valid measures with less adverse impact, it is legally appropriate to use hiring tools with adverse impact given that they are valid for predicting job performance of that particular job.

\section{Research Question}

Based on a review of the literature the following research question will be posed.

Do physical or social characteristics continue to im- 
pact the hiring decisions of applicants?

\section{Hypotheses}

The following hypotheses will be tested to provide guidance in this research.

H1: There is no statistical significance between physical characteristics and employability of applicants.

$\mathrm{H} 2$ : There is no statistical significance between social characteristics and employability of applicants.

H3. There is no statistical significance between weight and employability of applicants.

H4: There is no statistical significance between looks and employability of applicants.

H5: There is no statistical significance between perceived social status and employability of applicants.

\section{Methods Used in Research}

The hypotheses will be tested using data gathered from working adults attending college in the southeastern U.S.

\section{Data Collection Process}

A survey instrument asking a series of questions taken from the hypotheses were administered to working adults at a community college. The surveys were handed out in class and the instructor $l$ asked the students to complete the survey as part of a Human Resource Management course they are taking. They were not told they were being surveyed for a research paper to avoid variance in unrealistic answers. The surveys were collected by the instructor and the analysis took place using those survey responses. The survey Instrument is attached as Appendix I. A total of 87 surveys were returned complete and used for this study.

\section{Results and Findings}

The size (n) of this study is 87 and represents a convenience sample size for this study. The demographic statistics of the sample are 24 males and 63 females; 30 Caucasians, 43 Blacks, 8 Hispanics and 6 Asians; age groups $18-25=4 ; 26-30=29,31-35=18,36-40=12,41-$ $45=20$ and $46-50=4$. Correlation analysis was used as the statistical technique to analyze the data. The data can be seen in Appendix II.

The data was placed into Excel and then correlation statistical analysis was run on the data using the ten questions and the demographics as the two factors to be considered in a comparative analysis. An analysis of Hypothesis 1, which was taken from Questions 1, 2 and 10, provided the following information. Question 1 asked the respondent how important looks are to an applicant. The responses provided little to no correlation across all de- mographic areas and given this question alone the Hypothesis would have to be supported. Question 2 asked the importance of the applicant's height and provided a negative reaction from the respondents with an average mean of 1.58. This indicated the respondents had no interest in the height of the candidate they were interviewing. This was supported based on age and height of the respondents but on no other demographic factor. Given this question alone the Hypotheses would only be partly supported. Question 10 had the highest mean average of 4.43 where there was strong agreement that respondents were very concerned over physical appearance in dress of the applicant. This was supported by weight of the respondent but a negative correlation based on age. This question alone would not provide support for Hypothesis I. Therefore Hypothesis 1 could not be supported.

Hypothesis 2 was tested by using data from Questions 4 and 5 from the Survey. Question 4 sought information about age as a discriminating factor in the employment process. This was supported with a mean score of 2.58 which was expected. It shows strong correlation with age and race but showed moderate inverse correlations with height and weight. Findings indicate interviewers are not that concerned about age overall. Question 5 was asked to determine the respondents' reactions to one past as it relates to criminal background. This was a huge issue for females versus males but was inversely related based on the age of the respondent. This stigma supports other research findings that persons with criminal backgrounds, regardless of the crime or the amount of time that may have elapsed, continue to be discriminated against for employment. Based on the strong concern over criminal backgrounds this Hypothesis 2 cannot be supported.

Hypothesis 3 was tested using Question 3. This question was asked to determine if weight was a determining discriminatory factor in one's selection decision. Respondents were very opposed that eight was a factor at all with an average mean score of 1.65. Age of the respondent showed strong correlation that weight was not a factor while all other demographics showed little to any correlation. These findings are contradictory with the research in this area. It has been found in most studies that weight is a highly discriminatory factor in employment selection decisions [8]. This might be more of a sub conscious than conscious decision process. The findings indicate mixed support between the question and weight. Therefore the hypothesis is supported and accepted.

Hypothesis 4 was tested using Questions 1 and 2. This question was asked to confirm findings on physical appearance such as what one looks like. Question 1 provided neutral responses with an average mean of 2.38 and this was supported with virtually no correlation in 
any of the demographic areas. Question 2 had a negative reaction with a 1.50 average mean and was strongly supported by age and weight as demographic factors. Therefore the findings indicate that is no support between looks and height and employability. Age of the respondent is a driving factor in this decision process. Therefore the hypothesis is supported and accepted.

Hypothesis 5 was tested using Questions 6, 7, 8 and 9. These Questions were asked to determine if the applicant's external surroundings had any bearing on their acceptability as an applicant. Question 6 inquired about the applicant's educational level and received a neutral mean score of 3.09. Question 7 asked about the applicant's family life and had a negative mean average score of 1.98. Question 8 was asked to determine if one's history had any bearing on their employability. Respondents were almost neutral on this Question with a 2.80 average mean score. Findings indicate a strong correlation between Question 6 and gender, especially females. Question 7 correlated with race and age but had an inverse correlation with height of the respondents. Question 8 was very strongly correlated with age and correlated as well with females. Question 9 asked about the important of a person's family and received a negative reaction with an average mean score of 1.49. There was strong correlation among women, minorities and those over 40 years old. This would indicate support for Hypothesis 5 and is accepted and supported.

\section{Implications for Managers}

It is a company's responsibility to ensure that discrimination is kept at a minimum and that both employees and applicants have equal opportunity for success within the organization. Recent studies on sensitivity training show that this training is a valuable tool to promote workplace tolerance and mutual respect between employees from diverse backgrounds. [9] gives five actions that encourage a positive work environment. These actions include ensuring that guidelines are set in place to ensure that all employees know the discrimination policies and procedures and investigative measures that need to take place in the event that a claim is made. Secondly, [8] encourages meticulous documentation of all communication and especially if any exceptions are made to standard company policy.

As can be seen in these findings above one would expect respondents to provide answers that showed they would not be biased in an employment interview or selection process. However there were mixed responses to these questions that would allow for bias and discriminatory treatment to occur within an employment selection process unless strict measure and controls are not observed.

\section{Conclusions}

In order to provide fair and equal opportunities, interview questions must be predetermined and asked of all candidates, non-leading and open ended, based on job requirements and remain job related [10]. It is highly recommended that some solutions to these problems are to minimize the influence of racial and sexual stereotypes by providing interviewers with a job description and specifications of the potential job from which to make judgments. Secondly, the interview should remain job related and thirdly, interviewers ought to be thoroughly trained. Through training, interpersonal skills and decision making abilities can improve along with training interviewers how to focus on job related information. They should also be trained how to avoid matters such as questions that are not job related, making quick decisions about an applicant, stereotyping applicants and giving too much attention to a few characteristics. The training should also include how to get applicants to become at ease during the interview, communicating clearly with the applicant and maintaining consistency in the questions that are asked [11]. Training has the ability to improve effectiveness and efficiency of the selection process and decrease potential lawsuits for the organization.

The practical significance of this study is that even if discrimination is just perceived and is not a reality this perception leads to employee dissatisfaction and negatively affects the organization and its employees. Additionally, this perception could lead to a costly lawsuit for the company.

\section{REFERENCES}

[1] R. L. Daft, “Management,” 7th Edition, Thompson Learning, Mason, 2005.

[2] G. Jones and J. George, “Contemporary Management," 4th Edition, McGraw-Hill Companies, Inc., New York, 2005.

[3] J. Rosse and R. Levin, “High-Impact Hiring,” Jossey-Bass Publishers, San Francisco, 1997.

[4] J. Finkelman, "Discrimination, Harassment, and Retaliation: The Dysfunctional Side of Diversity," Consulting Psychology Journal: Practice \& Research, Vol. 59, No. 4, 2007, pp. 254-260. doi:10.1037/1065-9293.59.4.254

[5] “Personnel Selection: Methods: Interviews,” 2001. http://www.hr-guide.com/data/G311.htm

[6] “Race/Color Discrimination,” 2005. http://www.eeoc.gov/types/race.html

[7] “A Guide to Australia’s Anti-Discrimination Laws,” Information for Employers, 2005.

http://www.hreoc.gov.au/info_for_employers/law/index.h 
tml

[8] S. Cates, "Do Human Resource Professional Practice Self Fulfilling Prophecies? An Examination of Gender and Weight in the Context of an Employment Selection Decision Process,” UMI/ProQuest Publishers, Detroit, 1999.

[9] M. Worrall, “Sensitivity Training: FSB," Fortune Small Business, Vol. 19, No. 4, 2009, p. 72.

[10] D. Avery, P. McKay and D. Wilson, "What Are the Odds?
How Demographic Similarity Affects the Prevalence of Perceived Employment Discrimination," Journal of Applied Psychology, Vol. 93, No. 2, 2008, pp. 235-249.

[11] "Best Practice Guidelines for Recruitment and Selection," Information for Employers, 2004.

http://www.hreoc.gov.au/info_for_employers/best_practic e/recruitment.html

\section{Appendix I}

This Survey wishes to get your responses to the following questions. Please answer the questions as openly and honestly as possible. The results are confidential and will not be used with your name associated with them. Please circle that response that most closely identifies with you. Thank you for your participation.

1) I am interested in what a person looks like before I would hire them.

SD $\mathrm{D} \quad \mathrm{N} \quad \mathrm{A}$ SA

2) I am interested in how tall or short a person is before I would hire them

SD D N A SA

3) I am interested in how much a person weighs before I would hire them

SD $\mathrm{D} N \mathrm{~N}$ A

4) I am interested in how old a person is before I would hire them

SD D N A SA

5) I am interested in a person's criminal background before I would hire them

SD $\mathrm{D} \quad \mathrm{N} \quad \mathrm{A}$ SA

6) I am interested in where the person went to school or college before I would hire them

SD D N A SA

7) I am interested in a person's family life before I would hire them

SD $\mathrm{D} \quad \mathrm{N}$ A $\mathrm{SA}$

8) I am interested to know a person's past before I hire them

SD D N A SA

9) I am interested in a person's friends or family before I would hire them

SD $\mathrm{D} \quad \mathrm{N} \quad \mathrm{A}$ SA

10) I would be concerned about an applicant who came to an interview shabbily dressed and had hygiene issues

SD $\mathrm{D} \quad \mathrm{N} \quad \mathrm{A}$ SA

Tell us about you:

Male ___ Female

Race: White Black Hispanic Age: $18-25 \_26-30 \_31-35$ Asian Native American Other

Height Weight $41-45$ $46-50$ $51-55$ $56-60$ 


\section{Appendix II}

$\begin{array}{ccc}\text { Gender } & \text { Age } & \\ \mathrm{M}=24 & 18-25 & 4 \\ \mathrm{~F}=63 & 26-30 & 29 \\ & 31-35 & 18 \\ & 36-40 & 12 \\ & 41-45 & 20 \\ & 46-50 & 4\end{array}$

Race

White $=30$

Black $=43$

Hispanic $=8$

Asian $=6$
Height

$51^{\prime \prime}=1$

$52^{\prime \prime}=3$

$53^{\prime \prime}=9$

$5^{\prime} 5^{\prime \prime}=12$

$56^{\prime \prime}=17$

$57^{\prime \prime}=16$

5 '8" $=5$

$59^{\prime \prime}=7$

$5 ’ 10 "=6$

$5,11^{\prime \prime}=4$

$6^{\prime} 0^{\prime \prime}=3$

$6^{\prime} 1^{\prime \prime}=2$

$6^{\prime} 2^{\prime \prime}=2$

$$
\begin{gathered}
\text { Weight } \\
100-110=4 \\
111-120=8 \\
121-130=9 \\
131-140=21 \\
141-150=14 \\
151-160=10 \\
161-170=6 \\
171-180=7 \\
181-190=4 \\
191-200=2 \\
201-210=1 \\
210+=1
\end{gathered}
$$

Correlation Analysis:

$\begin{array}{lcccccccccc} & \text { Q1 } & \text { Q2 } & \text { Q3 } & \text { Q4 } & \text { Q5 } & \text { Q6 } & \text { Q7 } & \text { Q8 } & \text { Q9 } & \text { Q10 } \\ 18-25 & 2 & 2 & 2 & 2 & 4 & 4 & 2 & 4 & 2 & 4 \\ 26-30 & 2 & 2 & 2 & 3 & 4 & 3 & 1 & 3 & 1 & 5 \\ 31-35 & 1 & 1 & 1 & 1 & 1 & 5 & 2 & 3 & 1 & 5 \\ 36-40 & 4 & 2 & 2 & 2 & 2 & 4 & 3 & 4 & 2 & 5 \\ 41-45 & 4 & 2 & 2 & 2 & 3 & 4 & 2 & 4 & 2 & 4 \\ \text { Avg. Mean } & 2.38 & 1.50 & 1.65 & 2.51 & 4.07 & 3.09 & 1.98 & 2.80 & 1.49 & 4.43 \\ \text { Std. Dev. } & 1.45 & 0.59 & 0.73 & 1.29 & 1.08 & 1.05 & 1.06 & 1.10 & 0.88 & 0.64 \\ \text { Weight Correlation } & 0.02 & 0.04 & 0.02 & -0.12 & -0.06 & -0.05 & 0.05 & 0.09 & 0.00 & 0.17 \\ \text { Sex Correlation } & 0.00 & 0.09 & 0.09 & -0.07 & 0.20 & 0.18 & 0.04 & 0.14 & 0.19 & 0.01 \\ \text { Race Correlation } & 0.06 & 0.01 & 0.07 & 0.16 & 0.01 & 0.07 & 0.12 & 0.11 & 0.14 & 0.04 \\ \text { Age Correlation } & -0.03 & 0.19 & 0.20 & 0.18 & -0.19 & 0.02 & 0.11 & 0.20 & 0.20 & -0.17 \\ \text { eight Correlation } & 0.00 & -0.13 & -0.13 & -0.11 & -0.06 & 0.00 & -014 & -0.09 & 0.02 & -0.01\end{array}$

